SHORT REPORT

\title{
Distribution of sickness absence in the European Union countries
}

\author{
D Gimeno, F G Benavides, J Benach, B C Amick III
}

Occup Environ Med 2004;61:867-869. doi: 10.1136/oem.2003.010074

\begin{abstract}
Aims: To determine the sickness absence frequency in European Union (EU) countries.

Methods: Sickness absence was measured by questionnaire using the Third European Survey on Working Conditions. Employees were considered to have sickness absence if they reported to be absent at least one day in the past 12 months because of an accident at work, work related problems, or by other health problems.

Results: Sickness absence percentages were lower in Southern European countries compared with Central and Northern European countries, and, in general, slightly higher in men than in women.

Conclusion: This is the first description of sickness absence in each of the $15 \mathrm{EU}$ countries. Examination of the sickness absence patterning between EU countries could indicate countries where important lessons to reduce sickness absence are to be learned and diffused across the EU.
\end{abstract}

ost productivity, labour turnover costs, and long term disability burden have made sickness absence one of the - top policy priorities for European Union (EU) governments. ${ }^{12}$ Consequently, sickness absence, traditionally a public health surveillance measure, has emerged as an important indicator of a country's economic performance. Surprisingly little research has considered the feasibility of using sickness absence in cross national comparisons or as a performance indicator.

While national statistics for sickness absence exist in many countries of the EU, to our knowledge, only a few international comparisons have been performed in the past two decades, and a limited number of countries have been examined. One study compared data from Belgium, West Germany, and the Netherlands, ${ }^{3}$ and another one used data from Sweden and Norway. ${ }^{4}$ Recently, a comparative study has been conducted with the four European Nordic countries, France, the former West Germany, the Netherlands, and the United Kingdom, ${ }^{5}$ but the reference period for sickness absence was restricted to only one week. Differences in measures, sample design, and data collection make it difficult to establish appropriate between country comparisons. The scarcity of sickness absence research has been also attributed to the insufficient availability of comprehensive, reliable, and comparable data on sickness absence (that is, differences in legislation or case definition across countries) in the EU. ${ }^{126}$

However, international comparisons are urgently needed, since they may not only help in assessing a country's economic performance, but also enable overall patterns across countries to be observed, indicating which policies are working, for both public health and economic reasons. Additionally, research and intervention priorities can be identified from examination of sickness absence similarities and differences between countries. In spite of the measures utility, there is a lack of cross national epidemiological research assessing sickness absence frequency.

Taking into account all these issues, our aim was to determine the frequency of sickness absence in the past 12 months for 15 member states of the EU, assessing whether there were differences in sickness absence frequency in men and women.

\section{METHODS}

Since 1995 the European Foundation for the Improvement of Living and Working Conditions has incorporated standardised questions related to sickness absence in the European Surveys on Working Conditions. The Third European Survey on Working Conditions (ESWC), ${ }^{7}$ conducted in 2000, allows examination of sickness absence for the $15 \mathrm{EU}$ member countries. The ESWC was a multistage random sampling conducted on nationally representative samples of the total active population of all the EU countries, with the target to obtain 1500 persons in employment per country, except in the case of Luxembourg $(n=500)$. Persons in employment were defined as people aged 15 years and older doing any work for pay or profit during the reference week, or who had a job but was temporarily absent.

Between March and April 2000, a total of 21703 workers responded at home to a face-to-face interview in the national language of the country where they work. People who did not speak the national language were excluded. Countries' response rates were as follows: Germany $76 \%$, France $74 \%$, Spain 73\%, Luxembourg and Portugal 68\%, Austria 67\%, Sweden and Ireland 58\%, Belgium, Finland, and United Kingdom 56\%, Greece $47 \%$, Denmark $42 \%$, the Netherlands $41 \%$, and Italy $39 \%$. Response rates thus ranged from $39 \%$ in Italy to $76 \%$ in Germany. ${ }^{7}$ Participants were asked about their employment status (employed or self employed) and contract. Among those employed $(\mathrm{n}=17910)$, we excluded employees who were trainees or apprentices $(n=272)$ or those with missing information on their employment contract $(n=1240)$. Therefore, the analysis sample included 16398 employees. Additional methodological details are given elsewhere. ${ }^{8}$

Employees were classified as having sickness absence if they reported being absent at least one day in the past 12 months for any of the following health related causes: (a) "an accident at work", (b) "health problems caused by your work", or (c) "other health problems". Employees with information lacking on sickness absence $(\mathrm{n}=139)$ or with an incongruent number of absence days $(n=2)$ (that is, more than 365 days absent per year) were coded missing. Therefore, the analysis of sickness absence was based on 16257 employees. Age adjusted sickness absence percentages (that is, the proportion of employees with at least one day absent from work in the past 12 months among the total number of employees) and 95\% CI were computed using logistic regression models. ${ }^{9}$ 


\section{Main messages}

- Sickness absence percentages in Southern European countries were lower than in Central and Northern European countries.

- In most countries, men tended to show slightly higher percentages than women.

\section{RESULTS}

Table 1 reports the total number and age adjusted sickness absence percentages of each of the 15 member states of the $\mathrm{EU}$, together with the distribution by sex. Overall EU average sickness absence percentage was $14.5 \%$, varying between $6.7 \%$ in Greece and $24 \%$ in Finland. Comparing both sexes, men generally had higher sickness absence percentages in most countries. For both sexes, the lowest percentages were found in Greece (3.5\% in women and $8.9 \%$ in men), and the highest in Finland (25.7\% in women and $22.0 \%$ in men). In general, workers in Southern European countries reported less sickness absence than the EU average (Greece, 6.7\%; Portugal, 8.4\%; Italy, 8.5\%; Spain, $11.8 \%$; and France, 14.3\%). Percentages in those countries were lower than in Central European countries, except for the United Kingdom (11.7\%) and Ireland (8.3\%), and Northern European countries, except Denmark (12.4\%).

\section{DISCUSSION}

This paper is the first attempt to provided comparable sickness absence frequency data for each of $15 \mathrm{EU}$ member countries participating in the recent ESWC. ${ }^{7}$ Overall, lower percentages of reported sickness absence were found in Southern European countries compared with Central and Northern European countries and, in general, men showed slightly higher percentages than women.

This study relies on cross sectional self reported sickness absence data measured retrospectively for the previous year, which may introduce biases. ${ }^{10}$ Given the one year sickness absence recall period, memory bias is potentially present, which may overestimate the results. Also, a healthy worker effect might be present since employees with unusual work schedules or poor health status would have been more difficult to contact for the interview. This bias would underestimate the sickness absence percentages as inter-

\section{Policy implications}

- Increased public awareness of the sickness absence magnitude in the EU is needed.

- Comparable data on sickness absence across countries is needed.

- National interventions should be applied to reduce the burden of sickness absence.

viewed employees could be healthier, and possibly have less sickness absence than non-interviewed employees. Low response rates in Greece $(47 \%)$, Denmark $(42 \%)$, the Netherlands $(41 \%)$, and Italy $(39 \%)$ are another point of concern. Unfortunately, detailed non-respondent data are unavailable, restricting our ability to address limitations due to between country differential response rates. ${ }^{7}$

We used self reported sickness absence data instead of a more "objective" measurement such as a registry. ${ }^{11}$ The main practical reason for using self reports in large sample surveys, such as the ESWC, is that it might take considerable effort, if not be impossible, to obtain sickness absence registries from each respondent's workplace. ${ }^{12}$ Previous studies encountered many difficulties in obtaining complete sickness absence data for most of the employees from their companies. ${ }^{13}$ Another issue is that registries rely on medical certificates, which depend on a general practitioner's ability to determine when a worker must stop work and when a worker may return to work. ${ }^{14}$ Furthermore, employer practices and country legislation play a role. Self reports may have some advantages, since declaration instead of register could make sickness absence less dependent on employer practices and country and workplace legislation. ${ }^{11}$ Other studies have compared self reported sickness absence data with company records, finding that self reported sickness data can be a reliable source of absence data. ${ }^{15}{ }^{16}$ These studies are not conclusive and generalisable, since they focused on specific diagnoses, type of workers, and/or country. Furthermore, they based their analyses on the episode occurrence and duration data, which we did not collect. Despite the standardised data collection procedure, when interpreting the results there is no way of knowing whether differences between countries influence the way questions were understood. In addition, data on sickness absence spells were unavailable, limiting the

Table 1 Age adjusted percentage of employees with sickness absence* in each of the 15 member states of the European Union, 2000

\begin{tabular}{|c|c|c|c|c|c|c|c|}
\hline \multirow[b]{2}{*}{ Country } & \multirow[b]{2}{*}{$n$} & \multicolumn{2}{|l|}{ Total } & \multicolumn{2}{|l|}{ Men } & \multicolumn{2}{|c|}{ Women } \\
\hline & & $\%$ & $(95 \% \mathrm{Cl})$ & $\%$ & $(95 \% \mathrm{Cl})$ & $\%$ & $(95 \% \mathrm{Cl})$ \\
\hline Greece & 496 & 6.7 & (4.8 to 9.3$)$ & 8.9 & (6.1 to 12.8$)$ & 3.5 & (1.7 to 7.1$)$ \\
\hline Ireland & 1078 & 8.3 & (6.8 to 10.1 ) & 9.2 & (7.1 to 12.0 ) & 7.3 & (5.4 to 9.9$)$ \\
\hline Portugal & 1011 & 8.4 & (6.9 to 10.3 ) & 10.1 & (7.7 to 13.1$)$ & 6.8 & (5.0 to 9.3 ) \\
\hline Italy & 1025 & 8.5 & (6.9 to 10.4 ) & 9.9 & (7.8 to 12.5 ) & 6.4 & (4.4 to 9.2 ) \\
\hline United Kingdom & 1212 & 11.7 & (10.0 to 13.7 ) & 13.3 & (10.9 to 16.2 ) & 10.0 & (7.8 to 12.7 ) \\
\hline Spain & 1032 & 11.8 & (10.0 to 13.9 ) & 13.5 & (11.1 to 16.2 ) & 8.6 & (6.1 to 12.1 ) \\
\hline Denmark & 1221 & 12.4 & (10.7 to 14.4 ) & 12.9 & (10.4 to 15.8 ) & 12.0 & (9.7 to 14.8 ) \\
\hline France & 1212 & 14.3 & (12.4 to 16.4 ) & 15.4 & (12.8 to 18.3 ) & 12.9 & (10.4 to 16.0 ) \\
\hline Belgium & 1201 & 15.6 & (13.6 to 17.7 ) & 15.4 & (12.9 to 18.3 ) & 15.8 & (12.9 to 19.3 ) \\
\hline Austria & 1236 & 16.0 & (14.1 to 18.2 ) & 20.4 & (17.3 to 23.8 ) & 12.1 & (9.8 to 14.8 ) \\
\hline Sweden & 1323 & 17.0 & (15.0 to 19.1 ) & 14.9 & (12.3 to 17.9 ) & 18.8 & (16.1 to 21.9 ) \\
\hline Luxembourg & 425 & 17.4 & (14.1 to 21.3 ) & 21.4 & (16.8 to 26.7 ) & 11.1 & (7.1 to 16.9 ) \\
\hline Germany & 1265 & 18.3 & (16.3 to 20.5 ) & 21.1 & (18.2 to 24.4 ) & 15.0 & (12.3 to 18.2 ) \\
\hline Netherlands & 1367 & 20.3 & (18.3 to 22.6 ) & 21.8 & (18.9 to 25.1 ) & 18.9 & (16.2 to 22.0 ) \\
\hline Finland & 1153 & 24.0 & (21.6 to 26.6 ) & 22.0 & (18.7 to 25.7 ) & 25.7 & (22.4 to 29.3 ) \\
\hline Total & 16257 & 14.5 & (13.9 to 15.0 ) & 15.5 & (14.7 to 16.3 ) & 13.3 & (12.6 to 14.1$)$ \\
\hline
\end{tabular}

*Absent at least one day in the past 12 months by an accident at work, by health problems caused by the work, or by other health problems. 
possibility to take into account recurrent sickness absences in the analyses. Despite potential limitations, this study provides the first scientifically valid description of sickness absence across EU countries.

A simple explanation cannot be provided for our findings. Formally, paid sickness benefit level is limited in many countries, and it seems that countries with full pay periods for temporary work incapacity (that is Finland, Netherlands, Luxembourg, Austria, or Belgium) had higher sickness absence levels. ${ }^{1}$ In practice, however, full payment based on collective labour agreements is usual, although reductions could be applied as duration increases. The level of the payment may also vary, depending on several factors, such as employment time, being reduced among those employees having less time on the job. This may cause under-reporting of sickness absence, so that it cannot be taken as a direct estimate of morbidity. ${ }^{2}$ Consideration should be given to these issues in order to estimate the economic and disability burden of sickness absence across countries.

Since the purpose of the ESWC was not exclusively to measure sickness absence either across EU countries or by sex, the findings should be considered preliminary and should be interpreted with caution. In order to confirm our results, further detailed specific studies among EU countries should be conducted with specifically designed national surveys on sickness absence.

Nevertheless, to examine the overall patterns and differences in sickness absence in EU countries has some potential benefits. First, the data provide preliminary evidence as to how each EU country is performing. These data suggest where to look for practices which can be implemented. Second, learning from each other's best practices could improve our knowledge about this important public health and economic indicator. From a policy point of view, European governments should promote national interventions to reduce the burden of sickness absence in their countries. Finally, our research suggests establishing changes in the EU sickness absence legislation to make available comparable official data between EU countries.

\section{Authors' affiliations}

D Gimeno, F G Benavides, J Benach, Occupational Health Research Unit, Department of Experimental Sciences and Health, Universitat Pompeu Fabra, Barcelona, Catalonia, Spain

B C Amick III, School of Public Health, University of Texas-Houston Health Science Center, Houston, Texas, USA

Source of funding: This work was partly funded by the European Foundation for the Improvement of Living and Working Conditions, Dublin (Project 0156/Contract 00-3030-85)
Correspondence to: Dr D Gimeno, Southwest Center for Occupational and Environmental Health, The University of Texas School of Public Health, 1200 Hermann Pressler Street, PO Box 20186, Houston, Texas 77225-0186, USA; dgimeno@sph.uth.tmc.edu

Accepted 10 May 2004

\section{REFERENCES}

1 Gründemann RWM, van Vuuren CV. Preventing absenteeism at the workplace. Dublin: European Foundation for the Improvement of Living and Working Conditions, 1997.

2 Whitaker SC. The management of sickness absence. Occup Environ Med 2001:58:420-4.

3 Prins R, de Graaf A. Comparison of sickness absence in Belgian, German, and Dutch firms. Br J Ind Med 1986;43:529-36.

4 Sydsjo A, Sydsjo G, Kjessler B. Sick leave and social benefits during pregnancy-a Swedish-Norwegian comparison. Acta Obstet Gynecol Scand 1997;76:748-54

5 Bloch FS, Prins R, eds. Who returns to work and why? A six-country study on work incapacity and reintegration. London, UK: Transaction Publishers, 2001 ; (summary available at: http://www.issa.int/pdf/publ/ 2wirbooklet.pdf).

6 Benach J, Muntaner C, Benavides FG, et al. A new occupational health agenda for a new work environment. Scand J Work Environ Health 2002; 28:191-6.

7 Paoli P, Merllié D. Third European Survey on Working Conditions 2000. Dublin: European Foundation for the Improvement of Living and Working Conditions. Luxembourg: Office for Official Publication of the European Communities, 2001 (available at: http://www.eurofound.ie/publications/ files/EF0121EN.pdf).

8 Benach J, Gimeno D, Benavides FG. Employment status and health. Dublin: European Foundation for the Improvement of Living and Working Conditions. Luxembourg: Office for Official Publication of the European Communities, 2002 (available at: http://www.eurofound.ie/publications/files/ EF0221EN.pdf).

9 Garrett JM. Adjusted proportions. Stata Technical Bulletin 1998:43:sg33.1.

10 Checkoway H, Pearce N, Crawford-Brown DJ. Research methods in occupational epidemiology. New York: Oxford University Press, 1989.

11 Frese M, Zapf D. Methodological issues in the study of work stress: objective vs subjective measurement of work stress and the question of longitudinal studies. In: Cooper CL, Payne R, eds. Causes, coping and consequences of stress at work. Chichester, UK: John Wiley \& Sons, 1988.

12 Johns $\mathbf{G}$. How often you are absent? A review of the use of self-reported absence data. J Appl Psychol 1994;79:574-91.

13 Andrea H, Beurskens AJHM, Metsemakers JFM, et al. Health problems and psychosocial work environment as predictors of long term sickness absence in employees who visited the occupational physician and/or general practitioner in relation to work: a prospective study. Occup Environ Med 2003;60:295-300.

14 Feeney A, North F, Head J, et al. Socioeconomic and sex differentials in reason for sickness absence from the Whitehall II study. Occup Environ Med 1998:55:91-8

15 Severens JL, Mulder J, Laheij RJF, et al. Precision and accuracy in measuring absence from work as a basis for calculating productivity cost in the Netherlands. Soc Sci Med 2000;51:243-9.

16 van Poppel MNW, de Vet HCM, Koes BW, et al. Measuring sick leave: a comparison of self-reported data on sick leave and data from company records. Occup Med 2002;52:485-90. 